MATEC Web of Conferences 32, 06007 (2015)

DOI: $10.1051 /$ matecconf $/ 20153206007$

(O) Owned by the authors, published by EDP Sciences, 2015

\title{
Design of a vision guided quad-legged robot
}

\author{
Sukhee Park ${ }^{1}$, Kyuwon Jeong ${ }^{2}$ a \\ ${ }^{1}$ Dept. of Mech. Eng., Graduate School, CBNU, 361-763, Chungbuk, Korea \\ ${ }^{2}$ School of Mech. Eng., CBNU, 361-763, Chungbuk, Korea
}

\begin{abstract}
Legged robots are useful in the uneven terrain field than wheeled robots since they can have many kinds of gaits. In this paper a quadruped robot like a dog was designed and the gait was proposed for the stable walking. Its front two legs have joints for the outward or inward motion for the turnabout. Its hind two legs have joints for only the forward or backward motion. A camera was attached at the front upper position like a head. The object to be followed by the robot was captured by the camera and the relative position and the angle was obtained.
\end{abstract}

\section{Introduction}

Many kinds of mobile robots were developed in order to meet the given tasks. They use wheel or leg in order to have mobility. Since the motor driven wheel mechanism were developed long time, the design and fabrication of the wheeled robot is easier and widely used. However, it is suitable for the paved road or indoor floor. On the other hand, another type of mobile robot is that have legs. They are developed for the operation in the rough terrain for military purpose or security. For such legged robot a number of legs are used. If many legs are used it moves stably much more. But it become heavy and needs more energy. If less legs are used like humanoid robot, it needs complicated control system. So, the robot similar to the animal with 4 legs is researched by many research team.[1-11] The control system for such robot can be relatively simple and stability can be secured.

\section{Designed quad legged robot}

\subsection{Mechanism design}

The designed robot was shown in the figure 1.[12] It had four legs and a camera. The hind legs have three revolute joints which it could move in forward or backward direction by. On the other hand, the front two legs have 4 revolute joints and it could spread in or out the legs by rotating the joints attached at the shoulders. Besides that, any other links and joints were same as the hind legs. The parameters of the designed robot were shown in the table 1. The distance between front and hind leg was $420 \mathrm{~mm}$ and that between the left and right leg was $240 \mathrm{~mm}$. The total mass of the robot would be $10.35 \mathrm{~kg}$.
At each joint a servo motor which controlled the rotating angle would be installed. A camera was installed at the front upper position in order to capture the target object. Using the image for the object the robot would move toward the object.

\subsection{Gait diagram for stable walking}

Figure 2 shows the predefined sequence of a leg posture. In the figure the sequences from the $\mathrm{C}$ posture to the $\mathrm{G}$ posture, the foot is contact with ground and the

Table 1. Link parameters.

\begin{tabular}{|c|c|c|}
\hline Link No. & Length (mm) & Mass (kg) \\
\hline $\mathrm{L}_{1}$ & 53 & 0.065 \\
\hline $\mathrm{L}_{2}$ & 200 & 0.225 \\
\hline $\mathrm{L}_{3}$ & 120 & 0.139 \\
\hline $\mathrm{L}_{4}$ & 70 & 0.075 \\
\hline
\end{tabular}

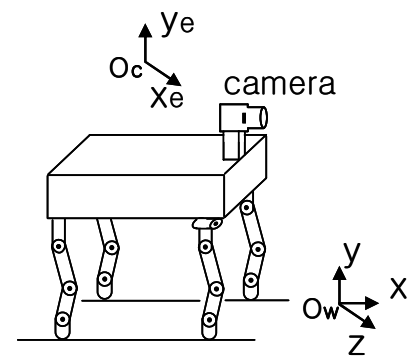

Figure 1. Designed 4 legged robot.

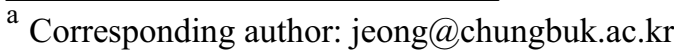




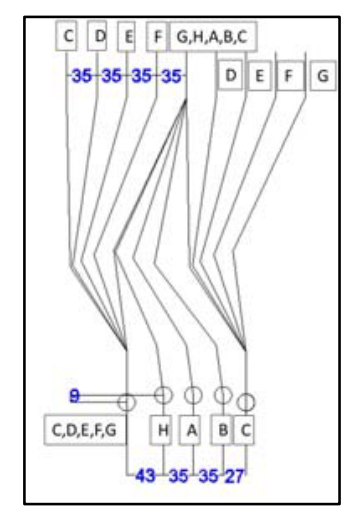

Figure 2. Leg stroke for a typical walking.

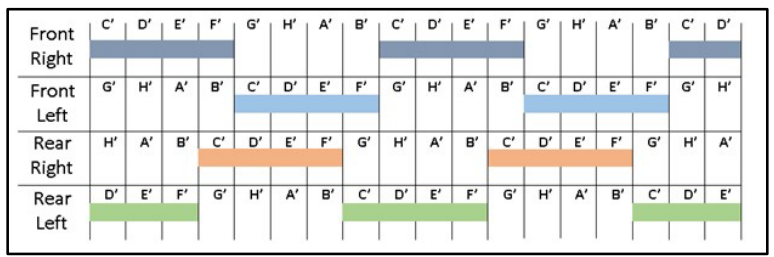

Figure 3. Gait Diagram.

shoulder moves toward. In the sequences from the $\mathrm{H}$ to the B the foot is off the ground and moves toward with the body. The joint angles were determined by imitating the leg motion of a real live dog walking on the plain ground. The sequences were applied to all of the four legs. Figure 3 shows the gait diagram for the leg locomotion. The prime symbol such as C', D', and so on, were the movement from the $\mathrm{C}$ posture to the $\mathrm{D}$ posture. As shown in the figure the gait pattern was repeated periodically. The bar meant that the foot was contact with ground during the movement. Two feet located diagonally was always contact with ground and the transition from contact to lift off was done while one leg was contact with ground. The gait was conducted as right trot, right pace, left trot, left pace, right trot, and repeatedly on.[2]

\subsection{Walking simulation}

The robot was modelled in the dynamics simulation software ADAMS in order to find out whether the proposed gait sequence work stable or not. The parameters such as body mass, etc. used in the simulation are shown in the table 1 and 2 . The simulated walking motion is shown in the figure 4 . The distance at one step is $261 \mathrm{~mm}$ in the simulation. As shown in the figure 1, y is the upward direction and $\mathrm{z}$ is the right hand direction. As the robot walked forward it wobbled up and down as shown in the figure 5. It will cause much difficulty to the guidance of the robot.

\section{Object position via camera}

In order to guide the robot toward the target object a camera was installed at the front upper part of the robot. The image coordinate of the object located at $(8000,400$,
Table 2. The parameters of the robot for the simulation.

\begin{tabular}{|c|c|c|}
\hline \multirow{4}{*}{ ADAMS } & $\begin{array}{c}\text { Interprocess } \\
\text { Option }\end{array}$ & PIPE(DDE) \\
\cline { 2 - 3 } & $\begin{array}{c}\text { Animation } \\
\text { Mode }\end{array}$ & Batch \\
\cline { 2 - 3 } & Communication & $0.01 \mathrm{~s}$ \\
\hline \multirow{2}{*}{ Matlab } & Simulation Time & $0 \sim 10 \mathrm{~s}$ \\
\cline { 2 - 3 } & Solver & $\begin{array}{c}\text { Ode45(Dormand- } \\
\text { prince) }\end{array}$ \\
\hline
\end{tabular}

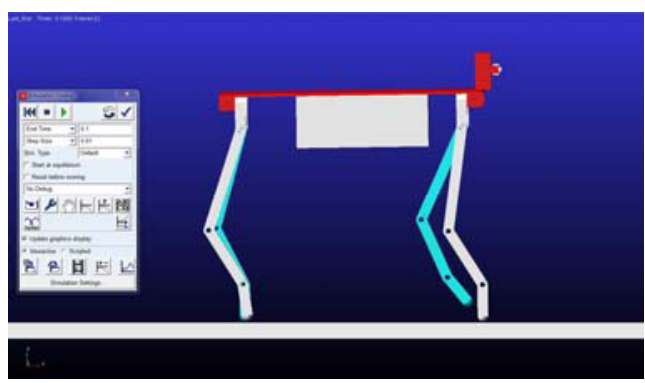

Figure 4. Walking simulation using ADMAS.

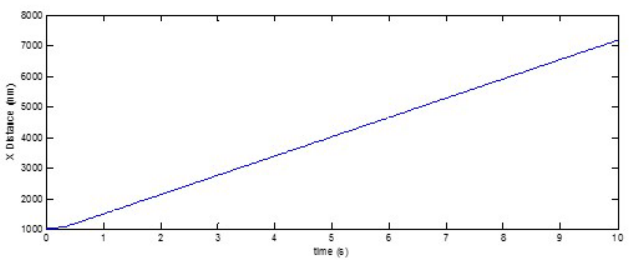

(a) X Direction

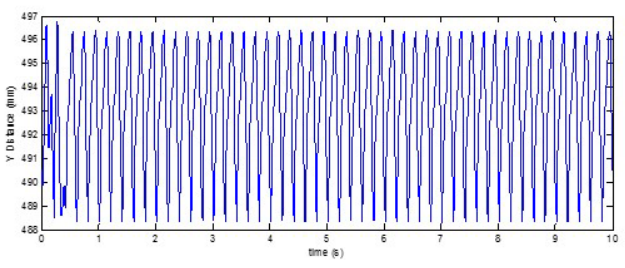

(b) Y Direction

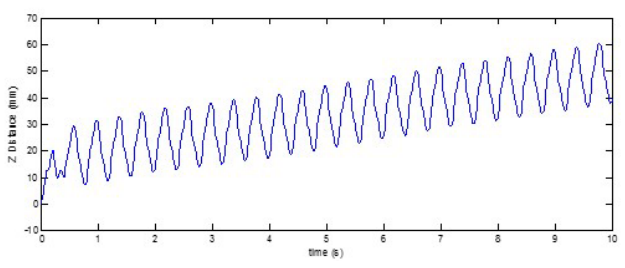

(c) Z Direction

Figure 5. Movement of the camera centre.

0) mm was obtained using the coordinate transformation which was implemented as shown in the figure 6 . The camera movement was extracted from ADAMS and it was fed to the Matlab simulink function module.[13,14] As shown in the figure 7 the coordinate of the object image was wobbled with the robot walking. 


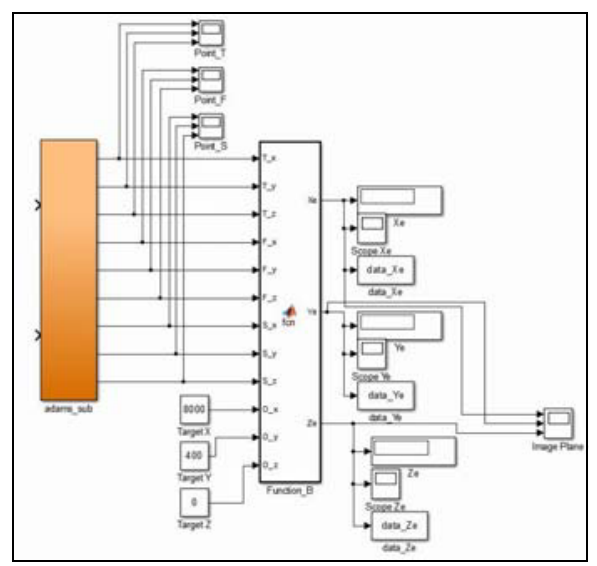

Figure 6. ADAMS-Matlab simulink model.

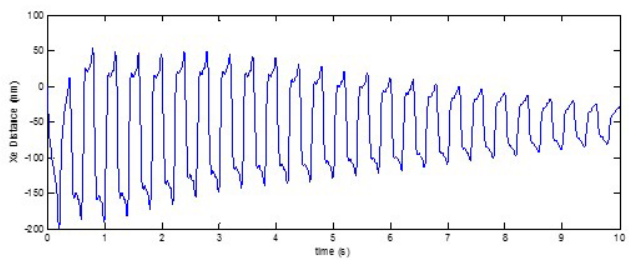

(a) Xe Direction

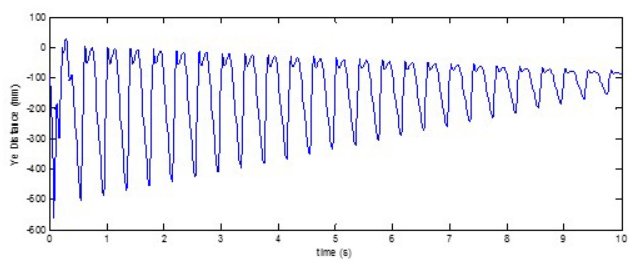

(b) Ye Direction

Figure 7. Centre position of the object image.

\section{Conclusions}

In this paper the gait was development for a designed quadruped robot and the movement of the object image were obtained. In order to guide the robot smoothly based upon the wobbled image coordinate a kind of image data processing algorithm and turnabout one will be developed.

\section{References}

1. B. Siciliano, O. Khatib, Springer handbook of robotics, 379-389 Springer-Verlag (2008)

2. D. C. Kar, J. Robotic Systems 20, 671-686 (2003)

3. B. L. Luka, D. S. Cookeb, S. Galtc, A. A. Collied, S. Chene, Robotics and Autonomous Syst. 53, 142-152 (2005)

4. I. M. Koo, D. T. Tran, Y. H. Lee, H. Moon, J. C. Koo, S. Park, H. R. Choi, Int. J. of Control, Auto., and Syst. 11, 1276-1289 (2013)
5. T. W. Tee, K. H. Low, H. Y. Ng, F. Young, 7th ICARCV, 826-832 (2002)

6. D. Pack and A. C. Kak, Proce. of IEEE/RSJ Int. Conf. on Intelligent Robots and Syst., (1994)

7. M. Raibert, K. Blankespoor, G. Nelson, R. Playter, the BigDog Team, Proc. of IFAC (2008)

8. E. Martinez, C. Torras, Pattern Recognition 34, 1585-1599 (2001)

9. K. Hosoda, T. Miyashita, S. Takeuchi, M. A sada, Proce. of the IROS '97, 778-784 (1997)

10. S. Kagami, K. Okada, M. Kabasawa, Y. Matsumoto, A. Konno, M. Inaba, H. Inoue, Proce. of Inter. Conf. on Intelligent Robots and Systems, 235-240 (1998)

11. S. Bazeille, V. Barasuol, M. Focchi, I. Havoutis,M. Frigerio, J. Buchli, C. Semini, D. G. Caldwell, Proce. of 2013 IEEE Int. Conf. on TePRA, (2013)

12. S. Park, Design of a quadruped walking robot and object tracking algorithm development, M.S. thesis, Dept. of Mech. Eng., Chungbuk National Univ., Korea, (2015)

13. ADAMS, Getting started using ADAMS/controls user guide.

14. Matworks Inc., Simulink user's guide. 